\title{
A Case of Solitary Cutaneous Leiomyoma on the Shoulder, Mimicking a Keloid: Case Presentation
}

\author{
Kanchan Kumawat ${ }^{1}$, Kailash Bhatia ${ }^{2}$
}

\begin{abstract}
Background: Cutaneous leiomyoma is a rare, benign smooth muscle neoplasm of the skin. According to the origin of the tumor, there are three types of cutaneous leiomyomas: piloleiomyoma, angioleiomyoma, and genital leiomyoma. We present an uncommon case of cutaneous leiomyoma which, due to clinical similarities, had been previously misdiagnosed and managed as keloid.

Case description: A 26-year-old woman with Fitzpatrick skin type 4/5 visited the outpatient department of dermatology for the treatment of a painful skin lesion on the left shoulder. The symptoms were not improving from previous treatment modalities, where she was diagnosed as having a keloid. After examination we sent for a skin biopsy. The specimen was sent for histopathological and immunohistochemical investigations, which revealed cutaneous leiomyoma.

Conclusion: Cutaneous leiomyoma may be misdiagnosed as a keloid. The former is of clinical relevance as they may denote hereditary leiomyomatosis and renal cell cancer. Early recognition is of paramount importance and may be life-saving.

Keywords: Cutaneous leiomyoma, Keloid, Skin biopsy.

The Journal of Medical Sciences (2020): 10.5005/jp-journals-10045-00151
\end{abstract}

\section{INTRODUCTION}

Cutaneous leiomyoma is a rare, benign smooth muscle neoplasm of the skin first described by Virchow in 1854. ${ }^{1}$ According to the origin of the tumor, there are three types of cutaneous leiomyomas, piloleiomyoma, angioleiomyoma, and genital leiomyoma. ${ }^{2}$ Keloid is an abnormal proliferation of scar tissue that forms at the site of cutaneous injury, especially after surgical incision or trauma. It does not regress and grows beyond the original margins of the scar. ${ }^{3}$ This case is an uncommon case of cutaneous leiomyoma which, due to clinical similarities, had been previously misdiagnosed and managed as keloid.

\section{Case Description}

A 26-year-old woman with Fitzpatrick skin type 4/5 visited the outpatient department of dermatology for the treatment of a moderate painful skin lesion on the left shoulder (Fig. 1). She had no history of previous keloid or scar. She denied history of surgery or trauma. There were no other keloid- or scar-resembling lesions in other regions of skin. No family history of similar or other cutaneous disorders. The symptoms were not improving from previous treatment modalities, where she had been misdiagnosed as having a keloid.

On examination: Inspection: Multiple erythematous papules coalescing to form plaque with diffuse surrounding erythema. Palpation: Warm, tender, firm dome-shaped swelling. Regional lymphadenopathy was absent. A punch biopsy of the skin was performed to confirm the diagnosis, with differential diagnosis of leiomyoma, lupus erythematous profundus, dermatofibroma and nodular BCC. Laboratory and histopathological evaluation were suggestive of leiomyoma with findings of nonepithelial neoplasm involving the reticular dermis with features of differentiation towards smooth muscles. The neoplastic cells showed abundant pink vacuolated cytoplasm and elongated wavy blunt-ended
${ }^{1}$ Department of Dermatology, Sawai Man Singh Medical College and Hospital, Jaipur, Rajasthan, India

${ }^{2}$ Department of Dermatology, Sri Aurobindo Medical College and PG Institute, Indore, Madhya Pradesh, India

Corresponding Author: Kanchan Kumawat, Department of Dermatology, Sawai Man Singh, Medical College and Hospital, Jaipur, Rajasthan, India, Phone: +91 9179286661, e-mail: dr. kanchankumawat90@gmail.com

How to cite this article: Kumawat K, Bhatia K. A Case of Solitary Cutaneous Leiomyoma on the Shoulder, Mimicking a Keloid: Case Presentation. J Med Sci 2020;6(2):34-35.

Source of support: Nil

Conflict of interest: None

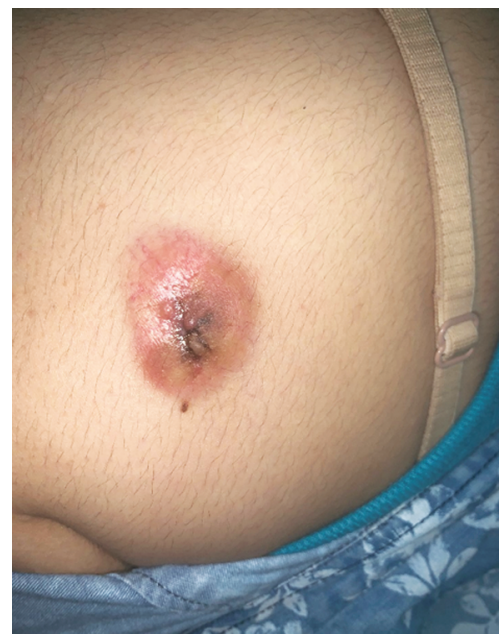

Fig. 1: Lesion present over the shoulder

(0) The Author(s). 2020 Open Access This article is distributed under the terms of the Creative Commons Attribution 4.0 International License (https:// creativecommons.org/licenses/by-nc/4.0/), which permits unrestricted use, distribution, and non-commercial reproduction in any medium, provided you give appropriate credit to the original author(s) and the source, provide a link to the Creative Commons license, and indicate if changes were made. The Creative Commons Public Domain Dedication waiver (http://creativecommons.org/publicdomain/zero/1.0/) applies to the data made available in this article, unless otherwise stated. 


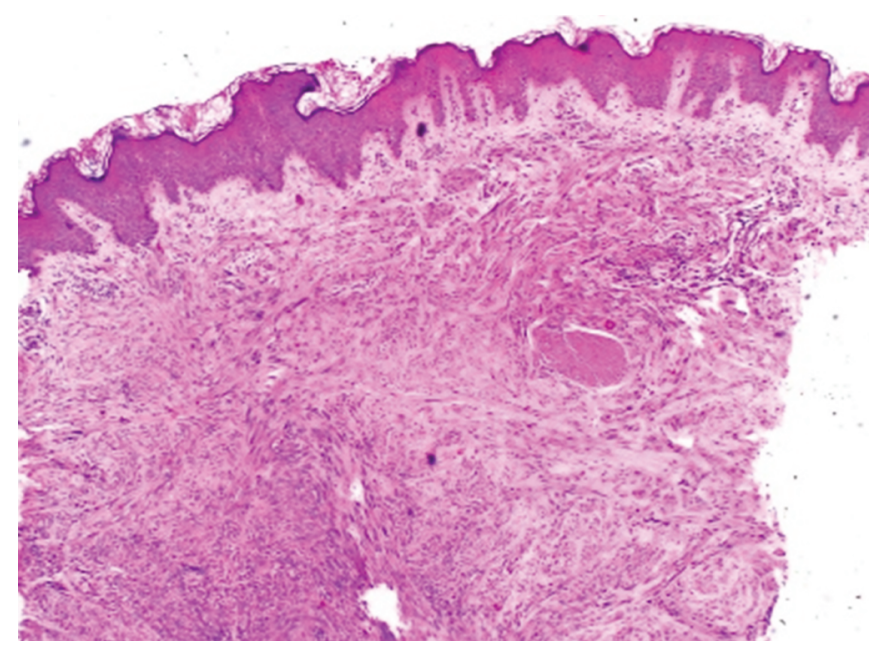

Fig. 2: Epidermis is unaffected. Neoplastic cells show abundant pink vacuolated cytoplasm arranged in small and long fascicles and dense collagen in the dermis $(H \& E \times 40)$

nuclei. The neoplastic cells are arranged in small and long fascicles that resemble normal erector pilorum muscle. Surrounding dermis shows dense collagen. Overlying epidermis is unaffected as shown in Figure 2. The patient was referred to the surgery department. Total surgical excision of lesions was performed.

\section{Discussion}

In our case, the lesions were situated on the shoulder, which is a typical location of the keloid. Leiomyomas also occur mostly in extremities and the next most common sit is the trunk. ${ }^{2}$ Leiomyomas could be single or multiple. They are painful skin lesions. They usually follow a benign course. ${ }^{2}$ Although the diagnosis of keloid was possible, we decided to perform a skin biopsy to confirm or exclude it. The histopathology supported the diagnosis of cutaneous leiomyoma. Hence, a dermatologist needs to perform a comprehensive evaluation of each patient presenting with various cutaneous lesions.

\section{Conclusion}

Cutaneous leiomyoma may be misdiagnosed as keloid. Early recognition is of paramount importance for proper management.

\section{References}

1. Virchow R. Uber amkroglossie und pathologische neubildung quergestreifter muskelfasern. Virchows Arch Pathol Anat 1854;7(1):126-138. DOI: 10.1007/BF01936233.

2. Fisher WC, Helwig EB. Leiomyomas of the skin. Arch Dermatol 1963;88(5):510-520. DOI: 10.1001/archderm.1963.01590230018002.

3. Wolfram D, Tzankov A, Pülzl P, et al. Hypertrophic scars and keloids - a review of their pathophysiology, risk factors, and therapeutic management. Dermatol Surg 2009;35(2):171-181. DOI: 10.1111/j.1524-4725.2008.34406.x. 